\title{
An Indirect Solution for Tampering EVM and Provision for Online Vote Casting and Authentication
}

\author{
Prof. Ravindra Babu Kallam, B. Abhinandraj, N. Rajesh and M. Santhosh Kumar. \\ Dept of Computer Science, \\ Aizza College of Engineering \& Technology, \\ Affiliated to JNTU, Mulkalla, Mancherial, Dist: Adilabad-504208, A.P, INDIA
}

\begin{abstract}
Election commission of India has marked with many significant changes in the recent time and it is considered to be one of the most responsible organizations. In such a big democratic country like India it is expected to adopt the latest technological options which improves the performance of voting and there of to achieve $100 \%$ polling in India by avoiding unauthorized users to cast voting.

In this paper we have given the solution for most of the problems we are facing in to days vote casting system. It will be very useful for Election Commission of India for its future enhancement.

The pictorial representation of our proposal and its process were explained. The merits and demerits of the existing and proposed system were discussed.
\end{abstract}

\section{General Terms}

Management, security, authentication, vote casting, Keil C

\section{Keywords}

EVM- Electronic Voting Machine

RAD- Rapid Application Development

\section{INTRODUCTION}

In the present elections polling system, the data is being maintained manually (Electoral rolls). It is time taking process for authentication of a voter and also it takes time to release the results[1].

It also needs high security for transportation of EVM's. Another challenge in front of the election commission is EVM tampering. Many experts have proven that the EVM machine can be tampered[1][2][3].

Security criteria for electronic voting [1][2][3][4][5][6][7] considers some basic criteria for confidentiality, integrity, availability, reliability, and assurance for computer systems involved in electronic voting. After an assessment of the reliability of those criteria, it concludes that, operationally, many of the criteria are inherently not satisfiable with any meaningful assurance.

Our project "An indirect solution for tampering EVM and provision for online vote casting and authentication" can be a solution for most of the mentioned problems.

It is a web based management solution proposed for Election Commission of India for its future enhancement and updated technology option in near future. This project is designed in view of complete maintenance of the voters details under any polling booth / polling station. It also takes care of online vote casting through EVM machine from any polling booth at a specified time.

Voter Authentication will be provided through online, using centralized database by the presiding officer. Election Related reports and results will generate easily by the Administrator when ever it is required.

\section{PICTORIAL REPRASENTATION}

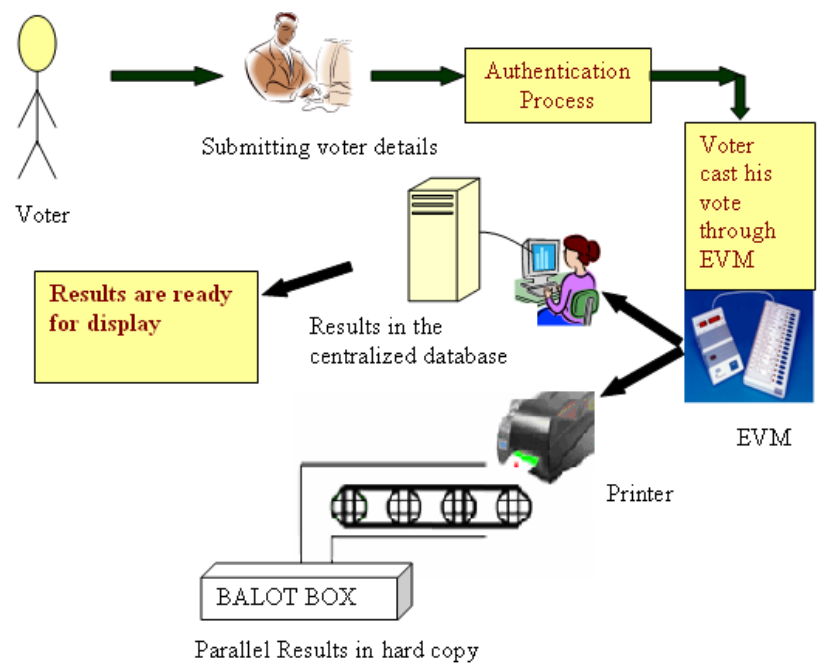

Figure 1 On line vote casting

\section{PROCEDURE}

Initially the Preceding officer has to get the access to system provided with internet facility and the EVM machine by entering his user name and password at the prescribed poling booth When voter comes to the polling booth, preceding officer verifies voter details by entering voter id and provides authentication. If voter id is valid then details of that voter is displayed and he is ready to cast his vote. If voter id is invalid then it displays invalid voter id and displays already voted if he castled his vote already. After the authentication, voter comes to the EVM machine and cast's his vote by pressing a button on EVM.

The result will be sent to the centralized election database [1] and an election symbol will be printed on the corresponding 
location of a ballot paper through a special printer and it will be moved to the ballot box through a glass chamber with some delay of time, so that the voter can verify his vote by observing it.

An important thing here is voter can only watch the ballot paper but he can't take that paper out. With this facility we can have results in two ways one is result available in centralized data base (readable soft copy) and the other is a ballot papers in the ballot box (hard copy). With this ability we can compare the results for verification on demand and hence it will be an indirect solution for EVM tampering.

Election related reports and results will generate easily when ever it is required by the admin or any authorized persons with respect to the privileges given by the election commission.

\section{CONCLUSION}

This project exposes the development of nation and it achieves a good result with respect to the factors of EVM tampering, rigging, missing voters, etc...Election related reports and results will generate easily when ever it is required by the admin or any authorized persons with respect to the privileges given by the election commission

The merits and demerits of existing and proposed system were explained. Process sequence with pictorial symbols were explained.

\section{FUTURE ENHANCEMENT}

We can also extend the authentication in to second level (first level with VOTER ID and password ) either by using thumb impression or by iris technology, so that we can avoid polling agents and casting vote by unauthorized voters.

With some changes we can vote from any where in the world from any internet center provided with thumb impression / Iris device on the same day.

We can use the same software with small modification to conduct elections for both assembly and the parliament at the same time and can also use for local body elections.
With small modifications we can use the same project for the entire country and even can conduct elections at a time.

\section{ACKNOWLEDGMENTS}

Our thanks to IJCA for allowing us to modify templates they had developed. We also like to thank our management of Aizza Engineering College for providing all the facilities to complete the task.

\section{REFERENCES}

[1] "Electronic Voting- A Survey", by Prashanth P.Bungale and Swaroop Sridhar, Department Computer Science, The Johns Hopkins University, www.cs.jhu.edu/rubin/courses/spo3/group-reports, 2002.

[2] "A Report on the feasibility of internet voting", California Internet Voting Task Force, January 2000.

[3] "Electronic Voting", Encyclopedia of computers and computer history, prepared by Lorrie Faith Cranor and edited by Ranl Rojas, published by Fitzroy Dearborn, 2001.

[4] “ Electronic voting”, Ronald L Rivest, Technical Report, Laboratory for computer Science, Massachusetts Institute of Technology.

[5] "Technical committee recommendations", California Internet Voting Task Force, January 2000.

[6] "A practical secret voting scheme for large scale elections", A.Fujioka, T.Okamoto, and K.Ohta, Advances in cryptology- AUSCRYPT-92

[7] "Secure Electronic Voting Over the WWW", Master's Thesis, Department of Electrical engineering and Computer Science, Massachusetts Institute of Technology, May 1999. 